\title{
Metodologia de apoio matricial: interfaces entre a Terapia Ocupacional e a ferramenta de organizaçáo dos serviços de saúde ${ }^{1}$
}

\author{
Camila Cristina Bortolozzo Ximenes de Souza ${ }^{a}$, \\ Simone de Pádua Ayres ${ }^{\mathrm{b}, \mathrm{c}}$, Estela Maria Maluf Marcondes ${ }^{\mathrm{d}}$
}

aTerapeuta Ocupacional, Departamento de Fisioterapia, Fonoaudiologia e Terapia Ocupacional, Mestranda do Programa de Pós-graduação, Departamento de Medicina Preventiva,

Faculdade de Medicina da Universidade de São Paulo - FMUSP, São Paulo, SP, Brasil

${ }^{\text {b} T e r a p e u t a ~ O c u p a c i o n a l, ~ C o o r d e n a d o r a, ~ e n t r e ~} 2004$ e 2010, de equipes do Núcleo de Apoio em Reabilitação - NAR e dos Núcleos de Apoio à Saúde da Família - NASF, Secretaria Municipal de Saúde. Especialista em Gestão da Clínica na Atenção Primária à Saúde, Serviço Educacional de Aprendizagem Comercial - SENAC Minas Gerais, Belo Horizonte, MG, Brasil

'Terapeuta Ocupacional, Núcleo de Apoio à Saúde da Família - NASF Galvão, Associação Saúde da Família, São Paulo, SP, Brasil

${ }^{\text {d} T e r a p e u t a ~ O c u p a c i o n a l, ~ A p r i m o r a n d a ~ e m ~ S a u ́ d e ~ C o l e t i v a, ~ F a c u l d a d e ~ d e ~ M e d i c i n a ~ d a ~}$ Universidade de São Paulo - FMUSP, São Paulo, SP, Brasil

\begin{abstract}
Resumo: O presente trabalho discute o apoio matricial como ferramenta de tranformação dos modos de organização na saúde, especificamente na atenção primária. Para isso, conceitua o tema e reflete sobre a crescente atuação do terapeuta ocupacional nas equipes de matriciamento desde a criação dos Núcleos de Apoio à Saúde da Família (NASF) pelo Ministério da Saúde. Busca-se problematizar as questões levantadas durante o grupo "Trabalho em Equipe e Matriciamento na Atenção Primária à Saúde" realizado em outubro de 2011, no I Simpósio de Atenção Primária do XII Congresso Brasileiro e IX Congresso Latino Americano de Terapia Ocupacional. Apresenta reflexões acerca de desafios encontrados na prática do apoio matricial no cotidiano de trabalho no NASF. Observou-se que os obstáculos encontrados na atuação têm paralisado os profissionais, porém valoriza-se, neste artigo, a importância de sua identificação como o primeiro passo para superá-los, bem como o papel do terapeuta ocupacional como um dos atores das transformações necessárias.
\end{abstract}

Palavras-chave: Apoio ao Planejamento em Saúde, Terapia Ocupacional, Atenção Primária à Saúde, Sistema Único de Saúde.

\section{Methodology for matrix support: interfaces between Occupational Therapy and the health care organizing tool}

\begin{abstract}
This paper discusses matrix support as a tool for transforming the ways of organizing health care, particularly concerning primary care. To this end, it conceptualizes the subject and reflects on the growing role of the Occupational Therapist in matrix teams since the creation of the Centers of Support for Family Health Care (NASF) by the Brazilian Health Agency. Moreover, it discusses the issues raised during the workshop on "Teamwork and matrix support in Primary Health Care" held in October 2011, at the Primary Health Care Symposium of the XII Brazilian Congress and IX Latin American Congress of Occupational Therapy. It introduces reflections on the challenges encountered in the practice of matrix support in the everyday work in the NASFs.
\end{abstract}

Autor para correspondência: Camila Cristina Bortolozzo Ximenes de Souza, Universidade de São Paulo, Rua Cipotânia, 51, Cidade Universitária, CEP 05360-160, São Paulo, SP, Brasil, e-mail: camila.reata@ usp.br

Recebido em 1/8/2012; Aceito em 12/9/2012. 
It was possible to observe that the obstacles found have been impairing workers' activities; nevertheless, what is valued in this article is the importance of the identification of these obstacles as the first step to overcome them, as well as the occupational therapist's role as one of the actors of the transformations needed.

Keywords: Health-planning Support, Occupational Therapy, Primary Health Care, National Health System.

\section{Refletindo sobre apoio matricial e equipe de referência}

O apoio matricial é uma metodologia de trabalho que vem crescendo no Brasil na maioria dos serviços da rede de Atenção Primária à Saúde devido, principalmente, à criação e à implantação dos Núcleos de Apoio à Saúde da Família (NASF), cuja metodologia é proposta em caderno de orientaçóes específico para o trabalho nesses serviços: Caderno de Atençẫo Básica do Ministério da Saúde n. 27 (BRASIL, 2009). Essas iniciativas são fruto de políticas recentes - como a portaria GM154/2008, que criou os NASF - , que têm favorecido a entrada de novos profissionais na composição e no fortalecimento das equipes da Atenção Primária à Saúde, entre eles o terapeuta ocupacional (GOZZI; SOARES, 2011). Contudo, parece ser necessário que o apoio matricial, como ferramenta potente de transformação dos modos de organizaçáo da assistência à saúde, seja mais discutido, pensado e apropriado pelos terapeutas ocupacionais.

Aqui, busca-se discutir a proposta de apoio matricial sugeridas por Campos e Domitti (2007) e suas implicaçôes para as práticas da terapia ocupacional no contexto da Atenção Primária à Saúde, mais especificamente em relação ao trabalho da terapia ocupacional no NASF. Vale destacar que as reflexóes aqui apresentadas foram inicialmente gestadas no grupo Trabalho em Equipe e Apoio Matricial, parte do I Simpósio de Atençáo Primária à Saúde realizado durante o XII Congresso Brasileiro e o IX Congresso Latino Americano de Terapia Ocupacional, realizados em São Paulo em outubro de 2011.

Inicialmente, é importante ressaltar que o apoio matricial não foi uma estratégia criada para o funcionamento dos NASF. O apoio matricial é uma metodologia de gestáo do trabalho em saúde proposta por Campos (1999) que objetiva garantir uma retaguarda especializada, capaz de oferecer tanto suporte técnicopedagógico quanto retaguarda assistencial.

$\mathrm{Na}$ expressão apoio matricial residem dois conceitos operadores: matricial e apoio. Matriz refere-se à mãe, aquela que gera e cria, também é um conceito que "[...] foi utilizado para indicar um conjunto de números que guardam relação entre si quer o analisemos na vertical, horizontal, ou em linhas transversais [...]" (CAMPOS; DOMITTI, 2007, p. 402). Matricial pressupóe que profissionais de referência e especialistas mantenham uma relação entre si, assim como campos de conhecimento de modo horizontal, de forma a gerar novos saberes e possibilidades de atuação, o que pode diminuir a fragmentação do cuidado. Apoio define-se por amparo, suporte, auxílio (CAMPOS; DOMITTI, 2007). É uma maneira de se operacionalizar a relação horizontal entre os profissionais, construindo linhas de transversalidade.

Vale enfatizar que o apoio matricial é uma ferramenta que apresenta duas dimensóes de suporte: assistencial e técnico-pedagógica. A dimensão assistencial é a que busca produzir ação clínica direta com os usuários; a ação técnico-pedagógica, por sua vez, visa produzir ação de apoio educativo com e para a equipe. Essas duas dimensóes não se separam: podem e devem estar integradas no cotidiano das açôes em saúde (BRASIL, 2009, p. 12).

No entanto, tal metodologia só pode ser operacionalizada à medida que as relaçóes entre equipe de referência e equipe de apoio matricial e seus diferentes saberes sejam horizontais, o que possibilita que novos saberes sejam gerados para ambas as equipes, permitindo que o cuidado ao usuário do sistema não seja pensado e executado de forma fragmentada (CAMPOS; DOMITTI, 2007).

Nessa perspectiva, é essencial que todos os saberes dos distintos profissionais da equipe sejam valorizados. Conforme aponta Campos (1999), a estrutura tradicional dos serviços de saúde costuma reforçar o isolamento profissional e reproduzir a fragmentação dos processos de trabalho, "[...] mantendo inquestionada a hegemonia do poder médico [...]" (p. 399). Assim, o apoio matricial e a equipe de referência não constituem apenas metodologias de trabalho, mas arranjos organizacionais que podem se mostrar potentes para diminuir a fragmentação imposta ao processo de trabalho decorrente da especialização cada vez maior das áreas do conhecimento (CAMPOS; DOMITTI, 2007).

Vale lembrar que esta metodologia prevê a corresponsabilização pela condução do cuidado, 
buscando abordagens mais integrais, pautadas em açóes interdisciplinares, uma vez que nenhum profissional pode, isoladamente, garantir cuidados integrais, construindo, assim, os projetos terapêuticos, acordando linhas de intervenção e distribuição de tarefas entre os vários sujeitos envolvidos no processo (CAMPOS; DOMITTI, 2007).

A participação da equipe de apoio em reuniôes de equipe, juntamente com a equipe de referência, é uma das estratégias possíveis para criar espaços de diálogo sobre temas clínicos de saúde e de gestáo, bem como para planejar açôes a serem realizadas em conjunto com as equipes de referência. Ressalta-se, contudo, que apenas tais açóes não caracterizam, por si só, um apoio matricial. Outro papel da equipe de apoio é realizar discussôes conjuntas para aproximar serviços de referência e contrarreferência, o que qualifica encaminhamentos, quando necessários, com mais responsabilidade.

Para que se possa pensar novas formas de atuação no contexto da Atenção Primária e do trabalho no NASF, é importante que o terapeuta ocupacional e outros profissionais possam criar estratégias e açóes diferenciadas para construir um novo modelo de atenção à saúde. Além disso, refletir sobre a articulação de suas ações com as políticas públicas, com o Sistema Único de Saúde, com o território e seus equipamentos sociais, assim como com as famílias envolvidas e com a construção do cuidado e da clínica ampliada.

Dessa forma, os integrantes da equipe NASF não se definem como orientadores das equipes de referência, ou debatedores de caso, muito menos encaminhadores. Muito além da retaguarda pedagógica, ou seja, da discussão de casos e temas relevantes para as equipes de referência, os profissionais do NASF também serão aqueles que realizarão atendimentos, compartilhados ou náo, individuais ou coletivos, no serviço ou no território, que se corresponsabilizarão pelos casos e que buscarão ampliar a resolutividade da Atenção Primária com seus saberes e práticas.

\section{Discussão acerca da construção do apoio matricial e do trabalho nos NASF: Desafios apontados durante o I Simpósio de Terapia Ocupacional na Atenção Primária à Saúde}

É pensando criticamente a prática de hoje ou de ontem que se pode melhorar a próxima prática. O próprio discurso teórico, necessário à reflexão crítica, tem de ser de tal modo concreto que quase se confunda com a prática [...] (FREIRE, 1996, p. 39).

Do grupo de trabalho Trabalho em Equipe e Apoio Matricial na Atenção Primária à Saúde realizado no I Simpósio de Terapia Ocupacional em Atenção Primária à Saúde participaram 31 pessoas, a maior parte delas do estado de Sáo Paulo, mas também do Rio de Janeiro, Goiás, Minas Gerais e Pernambuco. Entre elas havia 10 profissionais vinculados a serviços como NASF e unidades de saúde de nível ambulatorial, sendo as demais vinculadas a instituiçóes de ensino como estudantes de graduação ou de pós-graduação (residentes e mestrandos).

Os participantes levantaram algumas questôes relacionadas aos desafios da construção do matriciamento em seu cotidiano, no NASF. Sem negar a importância de todo o arcabouço teórico, no que concerne ao apoio matricial oferecido pelo NASF, concordamos com a perspectiva de Paulo Freire, sobre a necessidade de refletir criticamente sobre a prática para que esta possa paulatinamente se aproximar e se confundir com a teoria. Nesse sentido, conforme destaca o mesmo autor, "A teoria sem a prática é puro verbalismo inoperante, a prática sem a teoria é um ativismo cego [...]" (FREIRE, 2008).

Nas discussôes feitas pelo grupo evidenciou-se um desconhecimento, por parte de alguns presentes, acerca dessa metodologia de apoio matricial, assim como da Atençáo Primária em geral e das possibilidades da atuação da terapia ocupacional nesse contexto. Muitas pessoas pareciam não reconhecer a Atenção Primária como um campo de trabalho rico para a profissão, aparentando valorizar, ainda que sutilmente, a lógica de um modelo curativoreabilitacional centrado na doença, em tecnologias duras e nas especialidades.

Campos e Domitti (2007) narram obstáculos ao apoio matricial. Eles propóem cinco grupos principais de obstáculos: 1) estruturais; 2) decorrentes do excesso de demanda e da carência de recursos; 3) políticos e de comunicação; 4) subjetivos e de ordem cultural; 5) éticos; 6) epistemológicos. Ainda que tais obstáculos não tenham sido citados nas oficinas com esses nomes, é interessante detalhá-los aqui.

O obstáculo estrutural ocorre quando o modelo pensado para as equipes de apoio matricial - mais horizontal, dialógico e interdiscipinar - difere do modelo de organização institucional - verticalizado, hierarquizado e disciplinar. Para os autores, tal obstáculo necessita ser conhecido e quando possível enfraquecido, desconstruído, a fim de que se possa 
trabalhar em um sistema interdisciplinar e de cogestão.

O obstáculo excesso de demanda e carência de recursos ocorre por conta de um SUS ainda em construção e que por vezes tem de funcionar com carência de recursos e demanda excessiva. $\mathrm{O}$ apoio matricial é sugerido por Campos e Domitti (2007) como uma ferramenta que potencializa as equipes e sua resolutividade, de forma a contribuir para reduzir tais problemas.

O obstáculo político e de comunicação relaciona-se com a organização e funcionamento dos serviços de saúde, que concentram o poder em determinadas categorias profissionais, o que dificulta o compartilhamento do poder entre os distintos membros de uma equipe, assim como com os usuários. Sem que haja tal compartilhamento, o apoio matricial é questionável e por vezes se resume à supervisão de casos (e não discussão deles) realizada por uma equipe que diz-se de apoio mas que na verdade tem o papel de fiscalizar e corrigir ou manifestar a

[...] influência 'paterna' na solução de conflitos. [...] o método do apoio matricial depende da existência de espaços coletivos, ou seja, do estabelecimento de algum grau de cogestão ou de democracia institucional [...] (CAMPOS; DOMITTI, 2007, p. 404).

O obstáculo subjetivo e de ordem cultural é fruto de uma cultura de concorrência entre profissionais que dificulta a construção de um trabalho dialógico e interativo, com instâncias de mediação, espaços protegidos e processos de contrato em que se estabeleçam metas e critérios de avaliação do trabalho.

Trabalhar de forma interdisciplinar em uma equipe matricial exige do profissional uma predisposição subjetiva para receber e fazer críticas, para dialogar acerca de saberes e visóes de mundo e para tomar decisōes de modo compartilhado. Esse não é o padrão de subjetividade dominante em ambientes de concorrência, modo predominante nas nossas instituiçóes. Também é comum esse profissional apegar-se ao seu núcleo de formação como forma de identidade e segurança. Isso dificulta a interaçáo que é inevitável em espaços interdisciplinares.

O obstáculo ético esbarra no tema da privacidade e do segredo quanto à história do paciente, da família ou de grupos comunitários e é outro obstáculo relevante nesse tipo de trabalho, já que esse método busca a definição da responsabilidade sanitária de uma determinada população. Para Campos e Domitti (2007), a utilizaçâo do prontuário único pela equipe interdisciplinar, a discussáo do caso em equipe, toda essa circulação de informação obriga a que todas as profissóes de saúde repensem o tema das relaçóes entre elas e delas com os usuários.

O obstáculo epistemológico está relacionado ao fato de a maioria das profissóes de saúde trabalhar com um referencial sobre o processo saúde-doença restrito ao seu núcleo de formação. Para os autores, a clínica ampliada sugere maneiras para integrar as várias perspectivas em um método de trabalho que reconheça a complexidade e variabilidade dos fatores e dos recursos envolvidos em cada caso específico, individual ou coletivo. $\mathrm{O}$ apoio matricial é um dispositivo para a ampliação da clínica, para o trabalho interdisciplinar, e pressupóe algum grau de adesão a um paradigma que pense o processo saúde-doença e uma intervençáo de modo mais complexo e dinâmico (CAMPOS; DOMITTI, 2007).

Durante a oficina, diversas foram as dificuldades descritas pelos presentes. Muitas delas podem ser enquadradas em mais de uma das categorias de obstáculo. Os participantes apontaram a dificuldade que uma lógica de organizaçáo do trabalho hierarquizada e com pouca liberdade para os profissionais apresenta à construção do matriciamento. Alguns participantes narraram a dificuldade que a desconstrução de tal lógica apresenta, principalmente nas equipes de saúde da família onde o médico ainda aparecia como detentor do controle, saber e poder de decisão da equipe.

Outro desafio mencionado pelo grupo foi a dificuldade de construção de ações terapêuticas ocupacionais que extrapolem as açóes de orientação e discussão de temas ou casos específicos. Para os presentes que se pronunciaram sobre esse desafio, muitos serviços cobram participação dos profissionais do NASF em um número grande de reuniôes, o que inviabiliza qualquer outro tipo de ação, já que grande parte da carga horária dos profissionais fica reservada para essas atividades. Assim, parece difícil a construção de práticas de Atenção Primária mais resolutivas e menos "encaminhadoras".

Entretanto, a maioria dos participantes da oficina, em geral, reconhece o NASF como espaço interessante de atuação e campo de trabalho para os terapeutas ocupacionais, considerando-os importante facilitadores para a construçáo de modelos de atenção à saúde.

\section{Reflexões sobre o "amanhã"}

[...] a pura denúncia, a denúncia que não se alonga em anúncio, é uma denúncia que se castra. Todo anúncio tem que vir com um amanhã [...] (FREIRE; GUIMARÁES, 1986, p. 49).

Observou-se que os obstáculos têm paralisado os profissionais, porém sua identificação deve ser 
valorizada como o primeiro passo para transformá-los e superá-los. Portanto, eles devem produzir açáo, não paralisação. Nessa perspectiva é importante apostar na possibilidade de sensibilização da equipe para que mudanças nessas lógicas organizacionais sejam possíveis, a partir da validação dos diferentes saberes, conforme aponta Oury (1991).

Nessa perspectiva, um trabalho de sensibilização contribuiria para a identificação e possível superação de muitos obstáculos relacionados a cultura, comunicação, distribuição de poder nas equipes e nos serviços de saúde e na relação profissional de saúde e usuários. Contribuiria também para que o núcleo de profissionais apoiadores não fosse compreendido como os que sabem mais e, também, poderia se visualizar mais facilmente a diferença entre um trabalho de supervisão de caso e um trabalho de apoio matricial efetivo, já que o outro seria visto e compreendido em todas as suas potencialidades e particularidades. Da mesma forma seriam facilitadas relaçóes mais horizontais e na perspectiva de um trabalho interdisciplinar.

Campos e Domitti (2007) defendem a ideia de que é possível criar novos arranjos que produzam outra cultura e outras linhas de subjetivação nos serviços e equipes de saúde que não aquelas centradas no corporativismo e na alienaçáo dos trabalhadores e dos resultados de seu trabalho. Os autores ressaltam ser necessário inventar uma nova ordem organizacional capaz de estimular o compromisso das equipes com a produção de saúde, sem exigir delas "onisciência ou onipotência", permitindo-lhes, ainda, sua própria realização pessoal e profissional.

A partir do exposto, cabe refletir sobre a atuação do terapeuta ocupacional nesse contexto. Conforme discutem Rocha e Kretzer (2008), a inserção do terapeuta ocupacional na atenção primária tem como finalidade a ampliação dos atendimentos e realização e planejamento de programas para populaçóes com transtornos mentais e com algum tipo de deficiência, bem como garantir a integralidade da assistência.

Tais açóes de terapia ocupacional, como sugerem Rocha e Souza (2011), visam:

[...] desenvolver uma proposta dirigida a problemas coletivos e individuais de redução de incapacidades e deficiências, de melhora da qualidade de vida [...], de favorecimento da participação social, da constituição das redes sociais de apoio e da eliminação de preconceitos, discriminaçóes, exclusão social e segregação [...] (p. 40).

Como ressaltam as autoras, é importante que o trabalho do terapeuta ocupacional nesse nível de atenção também possa garantir que pessoas em sofrimento psíquico, com deficiência e/ou incapacidades, em situaçáo de vulnerabilidade social, dentre outras populações atendidas pela terapia ocupacional, tenham acesso à saúde e o consequente acesso aos demais níveis de atenção.

Além disso, a Atenção Primária mostra-se como locus privilegiado da atuaçáo do terapeuta ocupacional, pois devido à proximidade física entre serviços e moradia da população adstrita, permite um contato mais intenso e próximo do cotidiano dos usuários, famílias, amigos, sua cultura, território em que habita e por vezes até mesmo das escolas, locais de trabalho e lazer, assim como de outros equipamentos sociais utilizados pela população.

Tanto a garantia de acesso ao serviço de saúde quanto a compreensão do sujeito em seu cotidiano e contexto e o olhar cuidadoso à populaçáo-alvo neste cenário são elementos importantes do escopo de saberes da terapia ocupacional para agregar valor às discussóes de casos com a equipe NASF e com a equipe de referência, tanto para o planejamento de açôes em saúde com outros profissionais como para o desenvolvimento de ações de sensibilização e formação em saúde que, muitas vezes, são deixadas de lado neste nível de atenção, em detrimento de uma tradição de realização de açóes programáticas nas quais esta população e/ou questôes têm lugar diminuto.

A partir da demanda crescente de contratação de terapeutas ocupacionais em equipes de NASF, para apoio matricial, defende-se aqui que este profissional pode contribuir, também, na gestão do trabalho, utilizando suas especificidades de formação - como o olhar atento ao fazer, ao cotidiano e à participaçáo social - na percepçáo integral dos sujeitos (usuários e equipes). Conforme destacam Gozzi e Soares (2011), cabe ao terapeuta ocupacional, neste contexto profissional, desenvolver uma linguagem que favoreça e potencialize a comunicação com a equipe de referência, uma linguagem comum de discussão e de cuidado. As autoras apontam, ainda, que o encontro proporcionado na atenção primária entre equipe de referência, usuário e equipe matricial é desafiador, mas que se deve buscar a mudança da lógica do cuidado individual e especializado para o cuidado coletivo, territorial, regionalizado e transdisciplinar, construindo novas formas de atuação em saúde.

Finalizado o grupo de trabalho no simpósio, havia ainda muitas questôes e discussóes a serem desenvolvidas, muitas experiências a serem contadas, problematizadas, estudadas, mas que foram finalizadas por conta do tempo de duração da atividade. A tônica das perguntas de encerramento era: onde podemos nos (in)formar mais sobre o tema?

Como aquele era um espaço pontual dentro de um evento, houve a proposta de se continuar 
a discutir por meios eletrônicos. No entanto, tal forma de interaçáo é limitada, demorada, pois depende da resposta escrita e sua postagem, e por vezes é esvaziada.

Assim, faz-se necessária a construção de espaços de encontro entre terapeutas ocupacionais, e que possivelmente receba profissionais de outras áreas da saúde. Mais do que nunca mostra-se importante a divulgação de trabalhos de terapeutas ocupacionais sobre experiências com a metodologia de apoio matricial e a criação de espaços de discussão, grupos de estudo, de formaçóes que abordem e desmitifiquem o tema tanto na graduação quanto na pós-graduação.

\section{Referências}

BRASIL. Ministério da Saúde. Secretaria de Atençáo à Saúde. Departamento de Atenção Básica. Diretrizes do NASF - Núcleo de apoio à saúde da família (versão preliminar). Brasília: Ministério da Saúde, 2009. Disponível em: <http://bvsms.saude.gov.br/bvs/publicacoes/ caderno_atencao_basica_diretrizes_nasf.pdf $>$. Acesso em: jun. 2012.

CAMPOS, G. W. S. Equipes de Referência e Apoio Especializado Matricial: um ensaio sobre a reorganização do trabalho em saúde. Ciência e Saúde Coletiva, Rio de Janeiro, v. 4, n. 2, p. 393-403, 1999. http://dx.doi. org/10.1590/S1413-81231999000200013
CAMPOS, G. W. S.; DOMITTI, A. C. Apoio matricial e equipe de referência: uma metodologia para gestão do trabalho interdisciplinar em saúde. Cadernos de Saúde Pública, Rio de Janeiro, v. 23, n. 2, p. 399-407, fev. 2007. http://dx.doi.org/10.1590/S0102-311X2007000200016 FREIRE, P. Pedagogia da autonomia: saberes necessários à prática educativa. São Paulo: Paz e Terra, 1996.

FREIRE, P. Educar para transformar. Projeto Memória; Fundaçáo Banco do Brasil, 2008. Disponível em <http:// www.projetomemoria.art.br>. Acesso em: 12 nov. 2008. FREIRE, P.; GUIMARÃES, S. Sobre educação (Diálogos). Rio de Janeiro: Paz e Terra, 1986.

GOZZI, A. F.; SOARES, L. B. T. Solicitando o olhar do Terapeuta Ocupacional: o exercício do apoio matricial em uma Unidade de Saúde da Família de São Carlos - SP. Cadernos de Terapia Ocupacional da UFSCar, São Carlos, n. 19, 2011. Suplemento especial. CD-ROM.

OURY, J. Itinerários de formação. Revue Pratique, n. 1, p. 42-50, 1991. Traduçáo de Jairo I. Goldberg. Mimeo.

ROCHA, E. F.; KRETZER, M. R. Avaliação da Implantação das Açōes de Reabilitação no Programa da Saúde da Família (PSF) da Fundação Zerbini e Secretaria Municipal de Saúde de São Paulo - Região Sudeste - Sapopemba/Vila Prudente - periodo 2000/2006. São Paulo, 2008. Relatório de Pesquisa - Projeto CNPq. Mimeo.

ROCHA, E. F.; SOUZA, C. C. B. X. Terapia Ocupacional em reabilitação na Atenção Primária à Saúde: possibilidades e desafios. Revista de Terapia Ocupacional da Universidade de São Paulo, São Paulo, v. 22, n. 1, p. 36-44, abr. 2011.

\section{Contribuição dos Autores}

Todos as autoras contribuíram igualmente para a realização deste artigo.

\section{Notas}

${ }^{1}$ Este artigo é fruto de um grupo de discussão (intervenção) realizado na oficina Trabalho em Equipe e Matriciamento na Atenção Primária à Saúde em outubro de 2011, no I Simpósio de Atenção Primária do XII Congresso Brasileiro e IX Congresso Latino Americano de Terapia Ocupacional. 